\title{
Children use verb semantics to retreat from overgeneralization errors: A novel verb grammaticality judgment study*
}

\author{
BEN AMBRIDGE, JULIAN M. PINE and CAROLINE F. ROWLAND
}

Abstract

Whilst certain verbs may appear in both the intransitive inchoative and the transitive causative constructions (The ball rolled/The man rolled the ball), others may appear in only the former (The man laughed/*The joke laughed the man). Some accounts argue that children acquire these restrictions using only (or mainly) statistical learning mechanisms such as entrenchment and pre-emption. Others have argued that verb semantics are also important. To test these competing accounts, adults (Experiment 1) and children aged 5-6 and 9-10 (Experiment 2) were taught novel verbs designed to be construed - on the basis of their semantics - as either intransitive-only or alternating. In support of the latter claim, participants' grammaticality judgments revealed that even the youngest group respected these semantic constraints. Frequency (entrenchment) effects were observed for familiar, but not novel, verbs (Experiment 1). We interpret these findings in the light of a new theoretical account designed to yield effects of both verb semantics and entrenchment/pre-emption.

Keywords: Argument structure overgeneralization error; transitive; intransitive; semantic verb class hypothesis; entrenchment; no negative evidence problem; retreat from overgeneralization.

\section{Introduction}

Language acquisition can be seen as the process by which learners acquire the ability to generate (and - as a by-product — to judge the grammatical

* Thanks are due to Ben Bergen and two anonymous reviewers, and the children, parents and teachers who made this research possible. This research was funded by grant RES-062-230931 from the Economic and Social Research Council. Email: Ben Ambridge <Ben. Ambridge@Liverpool.ac.uk> 
acceptability of) utterances that they have not heard previously (Chomsky 1957). Whether constructions are considered to be meaningful units in their own right (as in construction grammar) or epiphenomenal and arising from verbs' syntactic selection properties (as under more traditional approaches), all researchers would agree that children must form (for example) some kind of [SUBJECT] [VERB] [OBJECT] transitive causative construction that allows for the generation of novel utterances. An important question is how, having formed a particular construction, children eventually learn that certain verbs may not appear in that construction (e.g. *Do you want to see us disappear our heads?; from Bowerman 1988). Although virtually all children make some overgeneralization errors, all eventually become adult speakers, who do not routinely produce such utterances, and rate them as ungrammatical in judgment tasks. Historically, the mechanisms by which this restriction process occurs have not been well understood.

Although some parents do seem to provide feedback when children produce an error (Farrar 1992; Saxton 2000; Chouinard and Clark 2003), an account based purely on this concept of negative feedback would incorrectly predict that adults should regard as grammatical any erroneous utterance for which they did not receive negative feedback as children (e.g. *The message emailed to John.). The notion of "blocking" (Marcus 1993) or "competition" (MacWhinney 1987) can account for "unlearning" of simple errors for which there is a direct competitor in the input (e.g. * sitted is blocked by sat). Problematic for such accounts, however, are argument-structure overgeneralization errors, which occur when a child uses a particular verb (e.g. the intransitive inchoative verb disappear) in an argument-structure construction in which it is not licensed in the adult grammar (e.g. the transitive causative [SUBJECT] [VERB] [OBJECT] construction; giving, for example *Do you want to see us disappear our heads?). The problem here is that there is no simple alternative form to block the error. The nearest would be a periphrastic causative (Do you want to see us make our heads disappear?) but many verbs can appear in both constructions, with slightly different meanings (e.g. break, stand up, grow; Bowerman 1988).

\subsection{The semantic verb class hypothesis}

One highly influential proposal is Pinker's (1989) semantic verb class hypothesis. Under this account, argument structure alternations (e.g. intransitive inchoative $\rightarrow$ transitive causative) are governed by broad-and narrow-range rules. To be a candidate for participating in the alternation, a verb must be consistent with the relevant broad-range rule (or "thematic core"). For this alternation, the broad-range rule specifies that the event must by dynamic (i.e. either GO or ACT, but not BE or HAVE). Thus non-dynamic verbs such as stay 
are not even candidates for appearing in this construction, and children are predicted not to make errors such as * She stayed it on the table. Not all verbs that are consistent with the broad range rule can participate in the alternation (e.g. disappear, fall, laugh). Thus children must form narrow-range semantic classes of verbs that may appear in particular constructions. When the classes have been fully formed, verbs that do not belong to one of the participating classes will no longer be used in the relevant construction. For example, verbs of "going out of existence" (Pinker 1989: 303) such as disappear and vanish form a class of verbs that can appear in the intransitive inchoative construction (e.g. The rabbit disappeared $)^{1}$. However, these verbs are not members of any class of verbs that appear in both the intransitive inchoative and transitive causative construction (e.g. verbs denoting "contained motion taking place in a particular manner" such as roll, bounce and skid; Pinker 1989: 130). Overgeneralization errors occur either because the narrow-range classes are not yet fully formed or because children have yet to fully learn the precise meaning of a verb and hence tentatively assign it to an incorrect class. Both adults and children may also make marginally ungrammatical "one-shot innovations" based on the broad range rule.

\subsection{Problems for the semantic verb class hypothesis}

Although Pinker's (1989) proposal has been highly influential, many authors have argued that it is fatally flawed, even as an account of the adult end-state. Both Braine and Brooks (1995) and Bowerman (1996; Bowerman and Croft 2007) raise the problem of negative exceptions: verbs that would appear to be semantically consistent with a particular class, but do not alternate. For example, Bowerman (1996) argues that overflow is consistent with the alternating class of verbs denoting an "externally-caused change of physical state"; yet it may not appear in the transitive causative construction (e.g. *You're gonna overflow the spoon with medicine, $\mathrm{C} 6 ; 7)$. A related problem is that errors with verbs that are stative as opposed to dynamic (e.g. *Why is the laundry stayed open all night?), which contravene the broad-range rule and hence are predicted to be completely absent, are in fact relatively frequent (Bowerman and Croft 2007; Pye and Loeb 1998). Bowerman (1988) also asks how children know that they must undertake the offline metalinguistic task of forming

1. In the present paper, we refer to such classes as intransitive-only (or non-alternating) classes. We use this term purely descriptively: Pinker's (1989) proposed mechanism does not form classes of verbs that do not alternate, as such classes would be unlearnable. Rather, verbs that are not members of a class that has been observed to alternate are designated, at some cut-off point in development, as non-alternating. 
semantic verb classes, particularly given that they do not know that some of their generalizations are in fact errors.

Another problem for Pinker's (1989) theory lies with its assumption of innate semantics-syntax linking rules. The operation that derives the transitive causative from the intransitive inchoative in fact operates on semantic as opposed to syntactic structures (roughly, ACTOR ACT $\rightarrow$ AGENT CAUSE [PATIENT ACT]). These innate linking rules then spell out the relevant syntactic structure (e.g. AGENT CAUSE [PATIENT ACT] $=$ [SUBECT] [VERB] [OBJECT]). However, as many authors (including Bowerman 1990, and even Pinker 1989, himself) have noted, the considerable cross-linguistic variation in the way that particular semantic roles are expressed syntactically renders the assumption of a set of innate linking rules problematic.

A final problem facing Pinker's (1989) theory is that it cannot account for verb frequency effects. Many studies (summarised shortly) have found that both children and adults rate overgeneralization errors as more acceptable for low-frequency verbs than higher-frequency verbs from the same semantic class (e.g. *The joke giggled/laughed him). Pinker's (1989) account cannot capture this phenomenon, because class membership is discrete as opposed to probabilistic: Either giggle is a member of the intransitive-only class of laughing verbs - in which case all errors should be equally unacceptable - or it is not - in which case such generalizations should be deemed grammatical. Whilst, for children, one could argue that low frequency verbs take longer to be assigned to the correct semantic class, Pinker (1989: 349) appears to rule out frequency effects for adults, arguing that "an adult's narrow-class rules correspond to the verbs that happen to alternate in her lexicon at a maturationally determined critical point, presumably around puberty".

\subsection{Statistical learning accounts}

Given the problems facing the semantic verb class hypothesis, some usagebased researchers, most notably Bowerman (1988; 1996), Braine and Brooks (1995) and Bowerman and Croft (2007), have argued that the learning procedure posited by Pinker (1989) is unfeasible, and that children instead retreat from error using statistical learning procedures such as entrenchment and preemption (discussed shortly). For example, in a recent paper in this journal, Stefanowitsch (2008: 527) argued that whilst "speakers might uncover certain semantic motivations for these [verb argument structure] constraints (for example, the 'narrow-class rules' suggested in ... Pinker 1989), ... those semantic motivations are not necessary for learning the constraint in the first place". In other words, the claim is that children can learn verbs' restrictions on a purely distributional basis, with verb semantics playing little or no role in the retreat from overgeneralization. 
One alternative proposal-Braine and Brooks' (1995) entrenchment hypothesis - posits that repeated presentation of a verb in attested constructions (e.g. the intransitive inchoative; The boy laughed) causes the learner to form an increasing probabilistic inference that the use of this verb in nonattested constructions (e.g. the transitive causative; *The joke laughed the man) is ungrammatical. In support of this proposal, judgment studies have shown that the unacceptability of errors increases (a) with increasing verb frequency (*The joke giggled/laughed the man) and (b) across developmental time, as attested uses strengthen this "inference from absence" (Theakston 2004; Ambridge et al. 2008, 2009; Stefanowitsch 2008; Wonnacott et al. 2007, for novel verbs; Brooks et al. 1999, in an elicited production study).

The pre-emption hypothesis (e.g. Goldberg, 1995; Boyd and Goldberg in press) is similar, except that errors (e.g. *The joke laughed the man) are blocked not by the use of the relevant verb in any construction (as for entrenchment), but only a construction that constitutes a near synonym (e.g. the periphrastic causative; The joke made the man laugh). There is some evidence that training children on the periphrastic causative construction can reduce the number of transitive overgeneralization errors produced (e.g. Brooks and Tomasello 1999; Brooks and Zizak 2002; though see Ambridge and Lieven 2011, for potential shortcomings of these studies).

\subsection{A role for semantics?}

Whilst the evidence for statistical learning effects is compelling, one recent study in particular suggests that verb semantics also play an important role in the retreat from overgeneralization (though in manner different to that argued for by Pinker, 1989). Ambridge et al (2008) taught adults and children aged 5-6 and 9-10 novel verbs that denoted novel laughing, disappearing and falling actions; all actions that are denoted by intransitive-only verbs in English (e.g. *The man disappeared/laughed/fell the woman). Two effects of verb semantics were observed. First, participants at all ages rated transitive causative uses, e.g. * The funny clown tammed Bart (= made Bart laugh), as unacceptable, relative to intransitive inchoative uses, e.g. Bart tammed (= laughed). Second, all age-groups rated transitive causative uses of the novel laughing verb, e.g. *The funny clown tammed Bart (= made Bart laugh), as more unacceptable than transitive causative uses of the novel disappearing verb, e.g. *The magician blicked Lisa (= made Lisa disappear), or falling verb, e.g. *The man meeked Lisa (= made Lisa fall) into a hole. This suggests some sensitivity to verb semantics at a fine-grained level: Since the transitive causative construction prototypically denotes direct, external, physical causation (e.g. one cannot say John crashed the car if John merely distracted the driver), verbs denoting actions that are not amenable to this type of causation (e.g. laughing actions) 
are particularly resistant to coercion (e.g. Croft 1991; Haspelmath 1993; Levin and Rappaport Hovav 1995; Marcotte 2005; Wolff 2003). A follow-up study (Ambridge et al. 2009) demonstrated that the ungrammaticality of overgeneralizations of intransitive-only verbs into the transitive causative construction could be ameliorated by increasing the directness of the implied causation ${ }^{2}$.

These findings suggest that children indeed use verb semantics to retreat from overgeneralization, though perhaps in a more fine-grained, probabilistic way than under Pinker's (1989) class-based account (an issue to which we return in the discussion). However, the study of Ambridge et al. (2008) is potentially problematic in that it also included English verbs from the same "semantic classes" as the novel verbs (i.e. laugh/giggle/novel; disappear/vanish/ novel; fall/tumble(novel). Whilst this manipulation allowed for simultaneous investigation of the entrenchment hypothesis (which was supported), it means that was possible, in principle, for participants to "succeed" with the novel verbs simply by adopting a strategy — determined on the basis of the familiar verbs - of rating all transitive causative sentences as ungrammatical.

\subsection{The present study}

The aim of the present study was to investigate whether adults (Experiment 1) and children (Experiment 2) can use the semantics assigned to novel verbs to determine the argument structure constructions in which they may and may not appear. This study provides a particularly stringent investigation of this possibility for two reasons. First, to avoid providing additional "clues", no semanticallyrelated English verbs were included. Second, the study included novel verbs that (on the basis of their semantics) alternate between the intransitive inchoative and transitive causative construction, as well as those that are (semantically) intransitive-only. To demonstrate knowledge of the constraints associated with verb meanings, participants must accept transitive causative uses of the former but not the latter. For adults (Experiment 1) we also included a frequency manipulation designed to provide a further test of the entrenchment hypothesis.

\section{Experiment 1 (Adults)}

In Experiment 1, adults were taught four novel verbs; two with intransitiveonly semantics (novel disappearing actions) and two with alternating seman-

2. Brooks and Tomasello (1999) found that children aged 4;5 and older (though not a younger group aged 2;5) produced more transitive causative utterances for a novel semanticallyalternating spinning verb than a novel semantically-intransitive-only ascending verb. However, this constitutes only suggestive evidence that children considered the latter to be ungrammatical, particularly as many nevertheless produced at least some transitive causative utterances with the novel ascending verb (for an overall average rate of $15 \%$ ). 
tics (novel spinning/rolling actions). Within each semantically-matched pair of verbs, one verb was presented with high frequency (72 presentations) and the other low frequency ( 24 presentations). All verbs were trained in intransitive inchoative sentences (e.g. The ball is tamming) only. At test, participants rated intransitive inchoative and transitive causative uses of each of the four novel verbs. The prediction is that participants should significantly prefer intransitive inchoative over transitive causative uses of the novel disappearing verbs, but - crucially — not the novel spinning/rolling verbs). A further prediction is that participants should rate transitive causative uses as more acceptable for the low frequency than the high frequency novel verbs (certainly for the nonalternating class, and possibly even for the alternating class).

\subsection{Method}

2.1.1. Participants. Participants were 37 native adult speakers of British English. The original sample comprised 48 participants, but 11 were excluded for failing to match the novel verbs to the relevant animations in a post test ${ }^{3}$.

2.1.2. Training. A within-subjects design was used such that participants were each taught four novel verbs: a high frequency verb (72 presentations) and a low frequency verb (24 presentations) from each of two "semantic verb classes"4 ("going out of existence": intransitive only; "manner of motion": alternating). Thus each participant was taught:

- A high frequency novel verb of "going out of existence" (e.g. meek) INTRANSITIVE ONLY

- A low frequency novel verb of "going out of existence" (e.g. tam)INTRANSITIVE ONLY

- Ahigh frequency novel "manner ofmotion"verb(e.g.fud)-ALTERNATES

- Alow frequencynovel"mannerofmotion"verb(e.g.dack)—ALTERNATES

The novel "going out of existence" actions were (a) 'wipe out' from top to bottom and (b) 'wipe out' from left to right. The novel "manner of motion" actions were (a) spinning alternately clockwise and anti-clockwise and (b) flipping

3. This is a relatively high exclusion rate, particularly for a study with adults. One possible explanation is that there was a high degree of confusability between the trials. The two actions within a given class were highly similar, and all were performed by the same set of objects. Another possibility is that the training schedule (weekly sessions) is non-optimal for this type of material, and that little learning was carried forward from the first two sessions.

4. Although we do not advocate discrete verb classes of the type proposed by Pinker (1989), we will sometimes use the term "semantic verb class" (as a shorthand for something like a probabilistic cluster of verbs with similar meanings), purely for convenience. 
backwards and forwards. The assignment of both phonological forms and (within each semantic class) meanings to verbs at the different frequency levels was counterbalanced across the initial cohort of 48 participants (drop-out rates were approximately even across all groups).

Each participant viewed three sets of training animations presented exactly one week apart (Ambridge et al. 2006, found that construction learning was most effective when training trials were temporally spaced, in this study, with a day between each training session). Each set consisted of 64 training trials: 8 for each of the two low frequency verbs and 24 for each of the two high frequency verbs. Each training trial consisted of a video animation where an inanimate object (e.g. cup, bowl, spoon, table) performed the relevant action against an interesting background (e.g. classroom, living room, beach). No other objects or characters were present. Each video was accompanied by a pre-recorded sentence in which the relevant verb appeared in an intransitive inchoative construction. To prevent the training from becoming overly repetitive, three different intransitive inchoative constructions (declarative, yes/no question, wh-question with answer) and three different tenses (past, present, future) were used. For example participants heard The cup meeked; Did the cup meek?; What meeked?, the cup did; The cup is meeking; Is the cup meeking? What's meeking? - The cup is; The cup's going to meek; Is the cup going to meek? and What's going to meek? - The cup is.

2.1.3. Test. The test phase was presented immediately after the final training session. Participants were given a written questionnaire containing one transitive causative and one intransitive inchoative sentence for each of the four training verbs. Participants were asked to rate each sentence for acceptability on a 7-point numerical scale, with 1 indicating "completely unacceptable" and 7 "completely acceptable". The agent and patient were novel, appropriate to the action, and the same for each high/low frequency pair within a given semantic class. For example, participants for whom meek and tam were verbs of "going out of existence" rated The magician meeked the rabbit, The magician tammed the rabbit, The rabbit meeked and The rabbit tammed. Within each counterbalance group, four different questionnaires with different agents and patients and different item orders were used. The questionnaire also included transitive causative and intransitive inchoative sentences containing high and low frequency English verbs from an intransitive-only semantic class ("motion in a particular direction": fall, tumble) and an alternating class ("change of state": break, smash). These items were included as fillers, and also served as control items, allowing us to check that participants were using the scale as intended. To ensure that participants could not use the English verbs to help with their novel-verb judgments, different verb classes were used for the novel and English verbs. 
2.1.4. Post test. After completing the questionnaire, participants completed a post test in which they were again shown each of the four novel actions and asked to match each to the appropriate novel verb form (meek, tam, dack or $f u d$ ). Eleven participants failed this task and were excluded from further analysis. This high drop-out rate may well be due to the high degree of confusability between the actions (e.g. wipe out top-to-bottom versus left-to-right). However, it was necessary for the high and low frequency verbs in each class to denote extremely similar actions, in order to control for potential fine-grained semantic effects.

\subsection{Results}

2.2.1. Novel verbs. Participants' mean ratings for the transitive causative and intransitive inchoative sentences containing each of the four novel verbs are shown in Table 1.

The first analysis investigated participants' ratings of the novel semantically alternating ("manner of motion") verbs. No effects of sentence type or verb frequency are predicted, since the verbs are semantically compatible with both the intransitive inchoative and transitive causative construction. A $2 \times 2$ (frequency by sentence type) within-subjects ANOVA confirmed this prediction, with no significant main effects or interactions observed. Most importantly, participants did not significantly prefer intransitive inchoative $(M=4.61, S E=0.29)$ over transitive causative $(M=4.27, S E=0.28)$ uses $(F 1,36=1.60, p=0.21$ n.s.) (though the means were in this direction, possibly as a result of exposure to exclusively intransitive inchoative sentences during training).

This finding is important as it demonstrates that participants do not show a preference for intransitive inchoative over transitive causative sentences for novel verbs that are semantically compatible with both constructions. That is, they do not show a preference for intransitive inchoative over transitive causative sentences across the board. This means that if participants $d o$ significantly prefer intransitive inchoative over transitive causative uses of semantically

Table 1. Adults' mean ratings (SD) for intransitive inchoative and transitive causative sentences containing each of the four novel verbs.

\begin{tabular}{llll}
\hline Semantics & Frequency & Intransitive & Transitive \\
\hline Going out of existence & High & $4.22(2.15)$ & $3.73(2.05)$ \\
$\quad$ (intransitive only) & Low & $4.46(2.18)$ & $3.62(1.75)$ \\
Manner of motion & High & $4.46(1.95)$ & $4.35(1.78)$ \\
$\quad$ (alternating) & Low & $4.76(1.89)$ & $4.19(1.88)$ \\
\hline
\end{tabular}


non-alternating, intransitive-only novel verbs, this effect cannot be due to a general preference for intransitive inchoative over transitive causative novel verb uses.

The second analysis investigated participants' ratings of sentences containing the semantically intransitive-only novel verbs (verbs of "going out of existence"). The prediction is that, on the basis of the verbs' semantics, participants should show a significant preference for intransitive inchoative over transitive causative uses. As predicted, a $2 \times 2$ within-subjects ANOVA with independent variables of frequency and sentence type yielded a significant main effect of sentence type such that participants significantly preferred intransitive inchoative $(M=4.34, S E=0.35)$ over transitive causative $(M=3.68, S E=0.28)$ verb uses $(F 1,36=5.24, p=0.03$, Partial eta squared $=$ 0.13 ). This effect can realistically be attributed solely to verb semantics. Importantly, it cannot be an effect of attested usage (recall that verbs were presented solely in intransitive inchoative sentences during training) as participants showed no such preference for semantically-alternating ("manner of motion") novel verbs that were also trained in intransitive inchoative constructions only.

The entrenchment hypothesis predicts an interaction such that the preference for the intransitive inchoative over the transitive causative sentence will be higher for the high- than the low frequency verb. However, no interaction of frequency by sentence type (nor any main effect of frequency) was observed (and, indeed, the means were not in this direction).

In summary, the findings from the novel verb analysis provide support for the existence of an effect of verb semantics but not of entrenchment. One possibility, however, is that the lack of an entrenchment effect is simply a consequence of the failure of the experimental manipulation to achieve a meaningful frequency difference between the "high" and "low" frequency verbs. One way to address this possibility is to investigate participants' ratings for English verbs.

2.2.2. English verbs. Participants also provided grammaticality judgments for intransitive-inchoative and transitive-causative uses of high and low frequency alternating (break/smash) and intransitive-only ( fall/tumble) English verbs (importantly these are NOT from the same semantic class as the novel verbs). These data are shown in Table 2.

The first analysis investigated the alternating English verbs (break and smash). Since these are acceptable in both the intransitive inchoative and transitive causative construction, we would not expect either construction to be preferred over the other for either verb (i.e. we predict no effect of verb semantics). Since all sentences are acceptable, we would also expect to see no effect of verb frequency. A $2 \times 2$ (frequency by sentence type) within-subjects 
Table 2. Adults' mean ratings (SD) for intransitive inchoative and transitive causative sentences containing each of the four English verbs.

\begin{tabular}{llll}
\hline Semantics & Frequency & Intransitive & Transitive \\
\hline Motion in a particular direction & High & $6.32(1.33)$ & $1.46(0.87)$ \\
$\quad$ (intransitive only) & Low & $6.00(1.81)$ & $2.68(1.63)$ \\
Change of state (alternating) & High & $6.03(1.69)$ & $6.43(1.30)$ \\
& Low & $6.03(1.62)$ & $6.14(1.65)$ \\
\hline
\end{tabular}

ANOVA confirmed this prediction, with no significant main effects or interactions observed.

The second analysis investigated the non-alternating, intransitive-only English verbs (fall and tumble). Here, the entrenchment hypothesis predicts an interaction such that participants' preference for grammatical (intransitive inchoative) over ungrammatical (transitive causative) uses will be larger for the high frequency verb ( $f a l l)$ than its lower frequency equivalent (tumble). A $2 \times 2$ (frequency by sentence type) within-subjects ANOVA confirmed this prediction, yielding a significant interaction of frequency by sentence type $(F 1,36=21.77, p<0.001$, Partial eta squared $=0.38)$ such that participants' preference for the intransitive inchoative over the transitive causative sentence was larger for the high frequency verb fall (intransitive $M=6.32, S E=0.22>$ transitive $M=1.56, S E=0.14$ ) than the low frequency verb tumble (intransitive $M=6.00, S E=0.30>$ transitive $M=2.67, S E=0.14$ ).

\subsection{Discussion: Experiment 1 (Adults)}

The findings of Experiment 1 demonstrate that, when asked to judge the acceptability of novel verbs in intransitive inchoative and transitive causative sentences, adults base their judgments on verb semantics, even when attested usage is held constant. That is, although all verbs were presented in intransitive inchoative sentences only, semantically-alternating novel verbs were judged as equally acceptable in the transitive causative construction, whilst semantically intransitive-only novel verbs were not.

Whilst a clear effect of verb semantics was observed, the results are more equivocal with regard to verb frequency (entrenchment) effects. Whilst overgeneralizations were rated as more unacceptable with high than low frequency intransitive-only English verbs (*The man fell/tumbled Bart into the hole), the same was not true for novel verbs. However, given that entrenchment effects have been observed in six previous studies (see Introduction), a fair conclusion is probably that both verb semantics and entrenchment effects are real, but that it is difficult to observe the latter by artificially manipulating the frequency of novel verbs. 


\section{Experiment 2 (Children)}

Whilst Experiment 1 demonstrated effects of verb semantics in adults, the crucial prediction of the account under investigation here is that children will also show such effects (recall that no judgment study has demonstrated this effect in the absence of English verbs from the relevant classes). Given that (a) we failed to find frequency (entrenchment) effects for novel verbs with adults and (b) such effects have already been demonstrated for English verbs with children of this age (Ambridge et al. 2008), we decided not to include a frequency manipulation in this study 5 .

\subsection{Method}

3.1.1. Participants. Participants were 26 children aged 5-6 $(M=5 ; 9)$ and 23 aged $9-10(M=9 ; 9)$. The original sample comprised 30 children at each age. However, four children from each group were excluded for failing the post-test, and three of the older children were unavailable for the final test session. Children were tested at their schools in the North West of England.

3.1.2. Grammaticality judgment training. Before the novel-verb training began, children completed a short pre-training session designed to familiarize them with the 5-point "smiley face" scale which they would later use to provide their judgments. Full details of this scale and training procedure can be found in Ambridge et al. (2008), which used an identical procedure. In brief, the experimenter completed two trials designed to illustrate maximally grammatical and ungrammatical sentences (The cat drank the milk $=5$; *The dog the ball played with $=1$ ) before inviting children to rate one further sentence of each type (The frog caught the fly=5; *His teeth man the brushed=1). Finally, children rated intermediate sentences $(*$ The woman said the man a funny story $=2 ; *$ The girl telephoned her friend the news $=3-4 ; *$ The man whispered his friend the joke $=3-4$ ) with the experimenter providing feedback.

3.1.3. Novel verb training. As in the adult study, children were taught two novel verbs: one semantically alternating ("manner of motion") and one semantically intransitive-only ("emotional expression"). The novel actions were (a) spinning alternately clockwise and anti-clockwise and (b) laughing in a particular high-pitched manner. The assignment of phonological verb forms (meek and tam) to these actions was counterbalanced across children at each age. Both verbs were presented in intransitive inchoative constructions only

5. Because the adults and children completed different training procedures, it would have been inappropriate to collapse the two datasets together for the purposes of statistical analysis. 
during training. As for the low-frequency verbs in the adult study, children heard a total of 24 presentations of each verb, split evenly across three sessions. In an attempt to improve verb learning, we presented these sessions on consecutive days (as in the study of Ambridge et al. 2006), as opposed to a week apart.

3.1.4. Test. The test session took place immediately after the final training session on Day 3. Children rated one intransitive inchoative and one transitive causative use of each of the two novel verbs (e.g. Marge meeked; The girl meeked Marge; Marge tammed; The girl tammed Marge) in random order, using the 5-point smiley face scale.

3.1.5. Post Test. As in Experiment 1, participants completed a post test in which they were asked to match each action to the appropriate verb form (meek or tam). Four children at each age failed this task and were excluded from further analysis.

\subsection{Results}

3.2.1. 9-10 year olds. As predicted, the novel semantically-alternating ("manner of motion") verb was rated as approximately equally acceptable $(t[22]=1.21, p=0.24$, n.s. $)$ in intransitive inchoative $(M=3.65, S D=1.58)$ and transitive causative sentences $(M=3.17, S D=1.59$; though the nonsignificant trend is towards favouring the attested usage). Importantly, this means that any preference for intransitive inchoative over transitive causative uses of the semantically non-alternating verb cannot be attributed solely to attested usage. Indeed, as predicted, the older children rated intransitive inchoative sentences with the novel intransitive-only ("emotional expression") verb $(M=3.91 ; S D=1.28)$ as significantly more acceptable than transitive causative overgeneralizations $(M=3.04, \mathrm{SD}=1.49 ; t[22]=2.21, p=0.04)$.

3.2.2. 5-6 year olds. The younger children displayed a virtually identical pattern of findings. Again, the novel semantically-alternating ("manner of motion") verb was rated as approximately equally acceptable $(t[25]=1.50$, $p=0.15$, n.s. $)$ in intransitive inchoative $(M=3.58, S D=1.33)$ and transitive causative sentences $(M=3.08, S D=1.57$; though, again, the non-significant trend is towards favouring the attested usage). Most importantly, the younger children also rated intransitive inchoative sentences with the novel intransitiveonly ("emotional expression") verb $(M=4.27 ; S D=1.25)$ as significantly more acceptable than transitive overgeneralizations $(M=3.35, \mathrm{SD}=1.60 ; t[25]=$ $2.46, p=0.02)$. 


\subsection{Discussion: Experiment 2 (Children)}

The findings of Experiment 2 demonstrate that, when asked to judge the acceptability of novel verbs in intransitive inchoative and transitive causative sentences, children as young as 5-6 base their judgments on verb semantics, even when attested usage is held constant: As for adults in Experiment 1, although both verbs were presented in intransitive inchoative sentences only, semantically-alternating novel verbs were judged as equally acceptable in the transitive causative construction, whilst semantically intransitive-only novel verbs were not.

\section{General Discussion}

The aim of the present study was to investigate whether (as found by Ambridge et al. 2008) children and adults use verbs' semantics to determine the constructions in which they can and cannot appear, and hence to retreat from overgeneralization error. The finding that both adults (Experiment 1) and children (Experiment 2) preferred intransitive inchoative over transitive causative uses of semantically intransitive-only verbs - but not semantically alternating verbs provides support for this view, and against the claim that children do not use verb semantics to retreat from overgeneralization error (Bowerman 1988; Braine and Brooks 1995; Bowerman 1996; Bowerman and Croft 2007; Stefanowitsch 2008). In view of the fact that entrenchment/pre-emption effects are also well attested in the literature (including, for English verbs, in our Experiment 1), what is needed is an account in which both verb semantics and entrenchment/pre-emption play a role. Whilst this has long been acknowledged by many usage-based theorists (e.g. Goldberg 1995; Tomasello 2003; Theakston 2004) we are aware of no detailed proposals for a unitary learning mechanism that can yield all three effects. Our goal in the remainder of the paper is to outline such an account (see Ambridge and Lieven 2011, for a more detailed version of this proposal and Ambridge submitted a, for a discussion of how the proposal can be applied to other phenomena).

\subsection{A new proposal: The 'FIT' account}

Although the account we present here, in this precise form, is novel, it draws heavily on much previous work in cognitive linguistics. For example, the idea that constructions (and their slots) are associated with particular meanings has been extensively discussed by (amongst many others) Langacker (1987), Goldberg (1995), Kay and Fillmore (1999) and Croft (2001). Most cognitive linguists would also share our assumption that speakers form slots that are associated with particular (e.g. semantic) properties by generalizing across concrete items that appear in a particular position, via a process known as schema- 
tization (e.g. Langacker 1987; Bybee 1995; Goldberg, 1995; Langacker 2000; Dąbrowska and Lieven 2005; Suttle and Goldberg in press). The claim that constructions compete to convey the speaker's intended message is familiar from the work of MacWhinney and collaborators (e.g. MacWhinney 1987, 2004), and has recently been worked out in some detail by Langacker (2000).

The central assumption of the proposal is that speakers generate novel utterances via the superimposition of a lexical item (in this case, a verb), into an appropriate slot in a construction (in this case a fully abstract [SUBJ] [VERB] $[\mathrm{OBJ}]$ transitive causative construction, though, in principle, constructions can be of any size and level of generality). The technical term for this process is unification (Kay and Fillmore 1999) or elaboration (Langacker 2000). When the properties of the item (e.g. break) and slot ([SUBJ] [VERB] [OBJ]) are sufficiently similar (where this is a matter of degree), a grammatical utterance results (e.g. The man broke the plate). Where the fit $^{6}$ between properties of the item and construction is poor, an ungrammatical utterance results (e.g. *The joke laughed the man). We share with Langacker (2000: 17) the assumption that

an expression is ill-formed to the extent that any [structures] involve extension rather than elaboration. We can expect many extensions to pass unnoticed in normal language use. It is only when a conflict is egregious, or when small conflicts have a cumulative effect, that the strain they produce rises to the level of conscious awareness.

Thus all overgeneralization errors involve the use of a lexical item in a construction slot with which it is less than optimally compatible in terms of its semantic, phonological, pragmatic, or other properties (an unacceptably high degree of extension or coercion; Goldberg 1995; Michaelis and Ruppenhofer 2001). In some cases, this may be not because an item is incompatible with a slot per se, but because there exists another construction that contains a slot with which the item would be more compatible (e.g. the periphrastic causative; The joke made the man laugh). Hence, this account incorporates the notion of competition (MacWhinney 2004) or pre-emption (Goldberg 1995; Boyd and Goldberg in press; Braine and Brooks 1995).

For the argument-structure overgeneralizations with which we are concerned here, the assumption is that compatibility is defined solely or primarily in terms of semantic properties. For example, in the case of * The man laughed the woman there is a clash between the semantic properties of laugh-singleparticipant internal causation - and the relevant slot in the transitive causative construction, which is associated with direct, external causation (e.g. one

6. Because the account emphasizes the importance of the fit between items and (construction) templates, it is termed the FIT account. 
cannot say John crashed the car if John simply distracted the driver, causing him to crash). For other types of overgeneralization error, the mismatch may be (morpho)phonological (e.g. The woman *donated/gave the library the book; Pinker 1989) or pragmatic ${ }^{7}$ in nature (there may also be other possibilities). It must be stressed here that compatibility (overlap between the properties of the item and the slot) is not absolute, but is a probabilistic, graded phenomenon. This is reflected in speakers' grammaticality judgments which are evenly distributed across a scale ranging from completely unacceptable to completely acceptable.

The utterance-formation process posited under the account is as follows (based on Langacker 2000). The speaker begins with a message that she wishes to convey. The message consists of a set of items - each of which is associated with a role - and a set of event-semantics features. For example, if a speaker wishes to convey the idea that a joke made a man laugh, the ITEMS[ROLES] would be JOKE[AGENT/CAUSER], MAN[PATIENT] and LAUGH[ACTION] and the event-semantics features would be CAUSE INDIRECT and PROCESS. To produce an utterance, a speaker must (1) choose an appropriate word (or phrase) for each item (e.g. the joke for JOKE, the man for MAN and laugh for LAUGH) ${ }^{8}$, (2) choose an appropriate construction (e.g. the periphrastic causative construction), and (3) insert each item into the appropriate slot in the construction. Importantly, each slot in each construction has its own probabilistic set of properties, determined by the shared properties of items that have appeared in that position in the strings that gave rise to the construction (Suttle and Goldberg in press). Every construction in the speaker's inventory competes for selection to convey the message (though in practice, most will have an activation level close to zero). The winner is the most highly activated construction, where the activation of each candidate construction is determined by fit (overlap between the properties of slots and their fillers), construction frequency (more frequent constructions will be more easily activated than less frequent constructions) item-in-construction frequency $^{9}$ (items in the message will activate constructions in which they have

7. With respect to pragmatic "overgeneralizations", so-called Principle C violations (e.g. She saw a snake next to $\operatorname{Sarah}_{\mathrm{i}}$ ) can be seen as the use of a full-lexical NP - with the pragmatic property of referring to a discourse-new referent-in a construction slot that is associated with the pragmatic property of referring to a discourse-old referent (Van Hoek, 1997). See also Kalyan's (submitted) reinterpretation of the study of Ambridge and Goldberg (2008), and a reply by Ambridge (submitted b), for a discussion of how so-called island constraints (e.g. *What did John whisper that Sue liked?) can also be interpreted in this manner.

8. For simplicity, we will use the term "item" to refer both to a semantic entity and the word/ phrase that labels it.

9. Type frequency of each slot in the construction (the number of different items that have appeared in the slot) is not posited as a separate factor as this factor will exert its influence via fit 
frequently appeared) and relevance. A highly relevant construction matches the message perfectly, in that it contains a slot for each entity in the message (e.g. if the message describes a highly causal event, an intransitive construction will score low on relevance, even though fit may be high).

Overgeneralization errors (e.g. * The joke laughed the man) occur when the child inserts into a slot an item that is a suboptimal fit for that slot. Thus the cause of overgeneralization errors is the child's failure to have acquired (a) an adultlike understanding of the properties of a particular slot or a particular item $^{10} \mathrm{OR}$ (b) an alternative construction which contains a slot that is a better fit for that item (here, the periphrastic causative). Overgeneralization errors cease as children refine and strengthen their knowledge of the properties of items and slots, and acquire alternative constructions with more suitable slots.

Apparent "semantic verb class" effects (Pinker 1989) arise because verbs that have similar semantic properties will inevitably be semantically (in)compatible with a particular slot to a similar degree. The account also yields entrenchment effects (a) via the effect of item-in-construction frequency (e.g. laugh will activate the intransitive construction-at the expense of the transitive - to a higher degree than will giggle) and (b) because high frequency items will have better-learned semantics. It also yields pre-emption effects (e.g. hearing laugh in a periphrastic causative blocks the use of this verb in the transitive causative), as the constructions that are most relevant for the message will naturally be the highest activated competitors (with no need to specify in advance which constructions compete with one another).

We end by summarising some of the ways in which we have begun to test the new account outlined previously. One strand of preliminary evidence in support of the proposal comes from studies involving the locative constructions. For the container locative construction [AGENT] [ACTION] [CONTAINER/LOCATION] with [CONTENTS] (e.g. Lisa filled the box with

(2). If many different items have appeared in a particular slot but they are all highly similar on some dimension, then (despite the high "type frequency" of the slot) new items that are not similar on that dimension may not appear in this slot. On the other hand, if only a handful of items have appeared in a particular slot but they are not particularly similar, then the slot will be open to new items. At the limit, even if only one item has appeared in a particular slot, a new item may appear in this slot, provided that it is extremely similar to the attested item (Suttle and Goldberg in press). As many authors have noted (e.g. Hare et al. 1995; Forrester and Plunkett 1994; Plunkett and Nakisa, 1997), morphological constructions behave in this manner with respect to phonological properties: A low-type-frequency construction (like the German [NOUN]s plural construction) can nevertheless be open to many new items, provided that the items that have previously appeared in this slot are phonologically dissimilar to one another.

10. Learning the semantic properties of an item (e.g. laugh) includes learning which particular elements of an event that item picks out or "lexicalizes" (e.g. the actions of the laugher, NOT the actions of another entity responsible for indirectly causing the laughter). 
paper), the [ACTION] slot is associated with the semantic properties of the container/location being completely affected or undergoing a change of state (e.g. going from empty to full). For the contents locative construction [AGENT] [ACTION] [CONTENTS] into/onto [CONTAINER/LOCATION], the $[A C T I O N]$ slot is associated with the semantic properties of the contents moving in a particular manner. Hence one can say Lisa filled the box with paper but not *Lisa filled paper into the box and Lisa spilled juice onto the floor but not *Lisa spilled the floor with juice. In an experimental study (Ambridge 2009), adult participants rated 142 verbs for each of 20 fine-grained semantic features thought to be relevant to the [ACTION] slot in each construction. In another part of the study, (different) participants rated contents and container locative uses of each of the verbs for grammatical acceptability. It was found that these semantic ratings could predict not only which verbs could appear in each of the two constructions, but also the relative ungrammaticality of overgeneralization errors.

Ambridge (submitted a) reported similar findings for the morphological unprefixation construction $(u n-V E R B)$. Although the semantic properties of verbs that may and may not appear in this slot are not easily characterized (enclosing, covering, surface attachment and circular motion; Whorf 1956; Li and MacWhinney 1996) adult participants' ratings of these properties could again predict the relative unacceptability of particular errors (e.g. *unbend, *unclose, *unfreeze), as judged by both adults and children. Ambridge et al (2009) also provided evidence from a judgment study that both adults and children know that the [AGENT] slot of the [AGENT] [ACTION] [PATIENT] transitive causative construction must be filled by a relatively direct causer.

Although preliminary, these findings - particularly those of Ambridge (submitted a) - suggest that children show a growing sensitivity to the semantic (and phonological etc.) properties of particular construction slots. However, since the account contains a large number of interacting factors, it will probably require implementation as a computational model (e.g. the Dual-path construction learning model of Chang 2002; Chang, Dell and Bock 2006) for its predictions to be fully testable. Ultimately, the aim is to extend this proposal to account for other types of "overgeneralization" error (see Ambridge submitted b; Ambridge and Lieven in press). We have already discussed how Principle-C and island-constraint violations can be seen under this account as pragmatic overgeneralizations. With regard to morphological overgeneralizations, for both adults (Albright and Hayes 2003) and children (Ambridge 2010), the acceptability of novel past-tense forms varies as a function of the phonological fit between the verb and the various regular and irregular morphological pasttense constructions.

In summary, the present studies have demonstrated that, for at least some verb classes and constructions, children and adults make use of verb semantics 
to determine the constructions in which particular verbs may and may not appear. We have proposed one possible learning mechanism that would yield this effect, whilst also yielding the effects of entrenchment and pre-emption that have been observed in a number of previous studies. Future studies should test this proposal (and any other future theoretical proposals that aim to account for these findings) more directly, with the aim of bringing the field closer to a complete account of how children form and appropriately restrict argument structure constructions.

Received 26 June 2009

University of Liverpool

Revision received 30 July 2010

\section{References}

Albright, Adam \& Bruce Hayes. 2003. Rules vs. analogy in English past tenses: A computational/ experimental study. Cognition 90, 119-161.

Ambridge, Ben \& Elena V. M. Lieven. 2011. Child language acquisition: Contrasting theoretical approaches. Cambridge: Cambridge University Press.

Ambridge, Ben. 2009. "Retreat" from argument-structure overgeneralization errors as a consequence of the acquisition of verb and construction semantics. Paper presented at the biennial meeting of the Society for Research in Child Development, April 2009, Denver: CO, USA.

Ambridge, Ben. 2010. Children's judgments of regular and irregular novel past tense forms: New data on the English past-tense debate. Developmental Psychology 46(6), 1497-1504.

Ambridge, Ben. submitted a. Testing a probabilistic semantic account of the formation and restriction of linguistic generalizations: A grammaticality judgment study.

Ambridge, Ben. submitted b. Island constraints and overgeneralization in language acquisition: A reply to Kalyan.

Ambridge, Ben, Anna Theakston, Elena V. M. Lieven \& Michael Tomasello. 2006. The distributed learning effect for children's acquisition of an abstract grammatical construction. Cognitive Development 21, 174-193.

Ambridge, Ben \& Adele E. Goldberg. 2008. The island status of clausal complements: evidence in favor of an information structure explanation. Cognitive Linguistics, 19(3), 349-381.

Ambridge, Ben, Julian M. Pine, Caroline F. Rowland, Rebecca L. Jones \& Victoria Clark. 2009. A Semantics-Based Approach to the "No Negative Evidence" Problem. Cognitive Science, 33(7), 1301-1316.

Ambridge, Ben, Julian M. Pine, Caroline F. Rowland \& Chris R. Young. 2008. The effect of verb semantic class and verb frequency (entrenchment) on children's and adults' graded judgements of argument-structure overgeneralization errors. Cognition. 106(1), 87-129.

Bowerman, Melissa. 1988. The "no negative evidence" problem: How do children avoid constructing an overly general grammar? In John A. Hawkins (ed.) Explaining language universals, 73-101. Oxford: Blackwell.

Bowerman, Melissa. 1990. Mapping thematic roles onto syntactic functions: Are children helped by innate linking rules? Linguistics 28, 1251-1289.

Bowerman, Melissa. 1996. Argument structure and learnability: Is a solution in sight? Paper presented at the Proceedings of the twenty-second annual meeting of the Berkeley Linguistics Society, Berkeley, California. 
Bowerman, Melissa \& William Croft. 2007. The acquisition of the English causative alternation. In Melissa Bowerman \& Penelope Brown (eds.) Crosslinguistic perspectives on argument structure: Implications for learnability. Hillsdale, NJ: Lawrence Erlbaum.

Boyd, Jeremy K. \& Adele, E. Goldberg. in press. Learning what not to say: The role of statistical preemption and categorization in 'a-adjective' production. Language.

Braine, Martin D. S. \& Patricia J. Brooks. 1995. Verb argument structure and the problem of avoiding an overgeneral grammar. In Michael Tomasello \& William E. Merriman (eds.) Beyond names for things: Young children's acquisition of verbs, 352-376. Hillsdale, NJ: Erlbaum.

Brooks, Patricia J. \& Michael Tomasello. 1999. How children constrain their argument-structure constructions. Language, 75(4), 720-738.

Brooks, Patricia J. \& Otto Zizak. 2002. Does preemption help children learn verb transitivity? Journal of Child Language 29(4), 759-781.

Brooks, Patricia J., Michael Tomasello, Kelly Dodson \& Laurence B. Lewis. 1999. Young children's overgeneralizations with fixed transitivity verbs. Child Development 70(6), 13251337.

Bybee, Joan. 1995. Regular morphology and the lexicon. Language and cognitive processes, 10(5), 425-455.

Chang, Franklin. 2002. Symbolically speaking: A connectionist model of sentence production. Cognitive Science 26, 609-651.

Chang, Franklin, Gary S. Dell \& Kay Bock. 2006. Becoming syntactic. Psychological Review 113(2), 234-272.

Chomsky, Noam. 1957. Syntactic structures. The Hague: Mouton

Chouinard, Michelle M. \& Eve V. Clark. 2003. Adult reformulations of child errors as negative evidence. Journal of Child Language 30(3), 637-669.

Croft, William. 1991. Possible verbs and the structure of events. In Savas Tsohatzidis (ed.), Meaning and Prototypes, 48-73. London: Routledge.

Croft, William. 2001. Radical construction grammar: Syntactic theory in typological perspective. Oxford: Oxford University Press.

Dąbrowska, Ewa \& Elena V. M. Lieven. 2005. Towards a lexically specific grammar of children's question constructions. Cognitive Linguistics 16(3), 437-474.

Farrar, Michael J. 1992. Negative evidence and grammatical morpheme acquisition. Developmental Psychology 28(1), 90-98.

Forrester, Neil, \& Kim Plunkett, K. 1994. Learning the Arabic plural: The case of minority default mappings in connectionist networks. Proceedings of the Sixteenth Annual Conference of the Cognitive Science Society. Hillsdale, NJ: Erlbaum.

Goldberg, Adele E. 1995. Constructions: A construction grammar approach to argument structure. Chicago: University of Chicago Press.

Hare, Mary, Jeff L. Elman \& Kim G. Daugherty. 1995. Default Generalisation in Connectionist Networks. Language and cognitive processes 10(6), 601-630.

Haspelmath, Martin. 1993. More on the typology of inchoative/causative verb alternations. In B. Comrie \& M. Polinsky (eds.) Causatives and transitivity. Amsterdam: John Benjamins.

Kalyan, Siva. submitted. Similarity in linguistic categorization, part 1: The role of shared features.

Kay, Paul \& Charles J. Fillmore. 1999. Grammatical constructions and linguistic generalizations: The What's $X$ doing $Y$ ? construction. Language 75(1), 1-33.

Langacker, Ronald W. 1987. Foundations of cognitive grammar, Volume 1. Stanford: Stanford University Press.

Langacker, Ronald W. 2000. A dynamic usage-based model. In Michael Barlow \& Suzanne Kemmer (eds.) Usage-based models of language, 1-63. Stanford: CSLI.

Levin, Beth \& Malka Rappaport Hovav. 1995. Unaccusativity: At the syntax-lexical semantics interface. Cambridge, MA: MIT Press. 
Li, Ping \& Brian Macwhinney. 1996. Cryptotype, overgeneralization, and competition: A connectionist model of the learning of English reversive prefixes. Connection Science 8, 3-30.

Macwhinney, Brian. 1987. The competition model. In Brian Macwhinney (ed.) Mechanisms of language acquisition, 249-308. Hillsdale, NJ: Erlbaum.

MacWhinney, Brian. 2004. A multiple process solution to the logical problem of language acquisition. Journal of Child Language 31(4), 883-914.

Marcotte, Jean. P. 2005. Causative alternation errors as event-driven construction paradigm completions. In Eve V. Clark \& Barbara F. Kelly (eds.) Constructions in acquisition. Stanford, CA: CSLI.

Marcus, Gary F. 1993. Negative evidence in language acquisition. Cognition 46(1), 53-85.

Michaelis, Laura A. \& Josef Ruppenhofer. 2001. Beyond alternations: A constructional model of the applicative pattern in German. Stanford: CSLI Publications.

Pinker, Steven. 1989. Learnability and cognition: The acquisition of argument structure. Cambridge, MA: MIT Press.

Plunkett, Kim \& Ramin C. Nakisa. 1997. A connectionist model of the Arabic plural system. Language and cognitive processes 12(5-6), 807-836.

Pye, Clifton \& Dianne F. Loeb. 1998. Experimenting with the causative alternation. Unpublished manuscript.

Saxton, Matthew. 2000. Negative evidence and negative feedback: Immediate Effects on the grammaticality of child speech. First Language 3(60), 221-252.

Stefanowitsch, Anatol. 2008. Negative evidence and preemption: A constructional approach to ungrammaticality. Cognitive Linguistics 19(3), 513-531.

Suttle, Laura. \& Adele E. Goldberg. in press. The partial productivity of constructions as induction. Linguistics.

Theakston, Anna L. 2004. The role of entrenchment in children's and adults' performance on grammaticality-judgement tasks. Cognitive Development 19(1), 15-34.

Tomasello, Michael. 2003. Constructing a language: A usage-based theory of language acquisition. Cambridge, MA: Harvard University Press.

Van Hoek, Karin. 1997. Anaphora and conceptual structure. Chicago: University of Chicago Press.

Whorf, Benjamin. 1956. Thinking in primitive communities. In John Bissell Carroll (ed.) Language, thought and reality. Cambridge, MA: MIT Press.

Wolff, Philip. 2003. Direct causation in the linguistic coding and individuation of causal events. Cognition 88, 1-48.

Wonnacott, Elizabeth A., Elissa L. Newport \& Michael K. Tanenhaus. 2008. Acquiring and processing verb argument structure: Distributional learning in a miniature language. Cognitive Psychology 56, 165-209. 